\title{
Instrumentos de Medida da Atividade da Artrite Reumatóide - Por que e como Empregá-los
}

\section{Pooled indices to measure rheumatoid arthrits activity - Why and how to use them}

\author{
Geraldo da Rocha Castelar Pinheiro(1)
}

Nos últimos anos, o conceito terapêutico da artrite reumatóide (AR) sofreu grande mudança. Três aspectos, em particular, passaram a ser base do novo paradigma de tratamento: a precocidade do diagnóstico, o início imediato das drogas modificadoras do curso da doença (DMCDs) e o controle rigoroso da atividade inflamatória.

Embora seja possível avançar, atualmente, os pacientes com manifestações articulares de caráter inflamatório têm chegado mais cedo para avaliação diagnóstica e tratamento. Há cerca de dez anos, em nosso serviço, o tempo médio do início dos sintomas articulares até o diagnóstico de AR era de quatro anos e meio ${ }^{1}$. Hoje, avaliando um grupo de cerca de 500 pacientes atendidos no ambulatório de $\mathrm{AR}$, o tempo médio do início dos sintomas ao diagnóstico diminuiu para 2,9 anos, com mediana de 1 ano. Em nosso meio, os ortopedistas e os clínicos são os especialistas mais envolvidos no atendimento dos pacientes com queixas articulares ${ }^{2}$. Apesar de já ter havido uma melhora, ainda se faz necessária uma boa divulgação, entre esses colegas, dos principais achados clínicos (artrite em mais de duas articulações, envolvimento das metacarpo/metatarsofalangeanas e rigidez matinal superior a 30 minutos) e laboratoriais [velocidade de hemossedimentação (VHS) e proteína C reativa (PCR) elevadas] que deveriam motivar o pronto encaminhamento do paciente com suspeita de AR para o reumatologista ${ }^{3}$. É importante, também, que os serviços de reumatologia tenham capacidade de atender essa demanda, em prazo que não inviabilize a abordagem pelo especialista de artropatia inflamatória de início recente.

O segundo aspecto, intimamente relacionado ao primeiro, é a introdução precoce de DMCDs. Está muito bem estabelecido que pacientes tratados com esses fármacos, ainda nas primeiras semanas de enfermidade, evoluem me- lhor que os que iniciam mais tardiamente 4 . O racional para essa conduta baseia-se no fato de que, nos dois primeiros anos do início dos sintomas, $75 \%$ dos pacientes apresentam erosões ósseas 5 . O conceito da "janela de oportunidade" salienta a necessidade do uso imediato das DMCDs, associadas ou não aos corticosteróides, visando ao controle precoce do processo inflamatório intra-articular, à prevenção da formação do pannus e da destruição da articulação acometida ${ }^{6}$.

Para que se otimize o tratamento das artropatias inflamatórias, faz-se necessária avaliação periódica da resposta clínica e laboratorial ao esquema terapêutico instituído. Em virtude da natureza multifacetada da $A R$, nenhum parâmetro clínico ou laboratorial, isoladamente, é capaz de traduzir, de forma satisfatória, o nível de atividade inflamatória em determinado momento.

Visando a minimizar o problema, foram criados os critérios de resposta do American College of Rheumatology $(\mathrm{ACR})^{7}$ e o critério de resposta e o índice de atividade de doença do European League Against Rheumatism (EULAR) ${ }^{8}$. Os índices compostos de atividade de doença (ICADs), o índice de atividade de doença - disease activity score (DAS $)^{8}$, como o índice de atividade de doença baseado em 28 articulações (DAS28) ${ }^{9}$, o índice simplificado de atividade de doença - simplified disease activity index (SDAI) ${ }^{10} \mathrm{e}$ o índice clínico de atividade de doença - clinical disease activity index $(\mathrm{CDAI})^{11}$ são instrumentos de grande utilidade para a medida da atividade da AR numa escala contínua.

O DAS é calculado a partir do índice articular de Ritchie - IAR ( 53 articulações avaliadas quanto à dor e ponderadas em: 0 - sem dor, 1 - dor leve, 2 - dor moderada e 3 - dor intensa), número de articulações edemaciadas (NAE) - 44 articulações, VHS e avaliação global de saúde (AGS) - escala

Recebido em 22/07/07. Aprovado, após revisão, em 14/09/07. Declaramos a inexistência de conflitos de interesse

1. Professor adjunto da Disciplina de Reumatologia da Faculdade de Ciências Médicas da Universidade do Estado do Rio de Janeiro (FCM-UERJ). Diretor científico da Sociedade Brasileira de Reumatologia.

Endereço para correspondência: Geraldo da Rocha Castelar Pinheiro, Avenida Nossa Senhora de Copacabana, 978, sala 508, 22060-002, Rio de Janeiro, RJ, Brasil e-mail: geraldo.castelar@gmail.com 
visual analógica (EVA) de 0 a 100. A fórmula empregada para o cálculo do DAS, no qual $\sqrt{ }$ é a raiz quadrada e ln é o logaritmo neperiano, é:

$$
\begin{gathered}
0,53938 \times \sqrt{ } \mathrm{IAR}+0,06465 \times \mathrm{NAE}+0,330 \\
\mathrm{x} \operatorname{lnVHS}+0,00722 \times \mathrm{AGS}
\end{gathered}
$$

O DAS28 utiliza, apenas, 28 articulações (ombros, cotovelos, punhos, metacarpofalangeanas, interfalangeanas proximais e joelhos, bilateralmente) e, em vez de empregar o IAR, utiliza o número de articulações dolorosas sem ponderar a intensidade da dor. Considera-se que seja dolorosa uma articulação que apresente algum grau de desconforto, não necessariamente dor intensa, quando avaliada pela dígito-pressão de sua interlinha ou por sua mobilização passiva. Assim como no DAS, a AGS é obtida por uma EVA (0 a 100).

Para o cálculo do DAS28, emprega-se a seguinte fórmula:

$$
\begin{gathered}
0,56 \times \sqrt{\mathrm{NAD} 28}+0,28 \times \sqrt{\mathrm{NAE}}+0,70 \\
\mathrm{x} \ln \mathrm{NHS}+0,014 \times \text { AGS }
\end{gathered}
$$

Uma calculadora própria para facilitar o cálculo do DAS e do DAS28 pode ser obtida, gratuitamente, pelo site www.das-score.nl.

Embora sejam avaliadas apenas as articulações dos membros superiores e os joelhos, o DAS28 demonstrou ótima correlação $(0,97)$ quando comparado com o DAS original e, naturalmente, é muito mais prático ${ }^{(9)}$.

Para avaliar se houve resposta clínica boa ou moderada ao tratamento instituído, levam-se em conta a melhora observada em relação ao DAS ou DAS28 inicial e o valor alcançado (Tabela 1).

O SDAI é o único ICAD que emprega cinco parâmetros e tem como grande vantagem o cálculo mais simplificado, uma vez que seu resultado é obtido pela soma simples de seus componentes (Tabela 2). Além disso, em vez de empregar a VHS, mais sujeita a alterações não relacionadas, necessariamente, com a inflamação, a PCR é o parâmetro laboratorial de avaliação de inflamação.

O resultado do CDAI também é obtido pela soma simples de seus componentes. Tem como grande diferencial a ausência de parâmetro laboratorial, permitindo ser calculado em tempo real, no momento da consulta médica (Tabela 2).

Os níveis de atividade de doença para os diversos ICADs

\begin{tabular}{|c|c|c|c|c|}
\hline \multirow{2}{*}{\multicolumn{2}{|c|}{$\begin{array}{c}\text { DAS - DAS28 } \\
\text { alcançado }\end{array}$}} & \multicolumn{3}{|c|}{ (Melhora em relação ao valor inicial) } \\
\hline & & $>1,2$ & $\leq 1,2$ e $\leq 0,6$ & \\
\hline \multirow[t]{2}{*}{$\leq 2,4$} & $\leq 3,2$ & Boa resposta & \multirow{2}{*}{ Resposta moderada } & \\
\hline & & & & \\
\hline $\begin{array}{l}e, 4,7 \\
e 3,7\end{array}$ & $e \leq 5,1$ & & \multirow{2}{*}{\multicolumn{2}{|c|}{ Sem resposta }} \\
\hline$>3,7$ & $>5,1$ & & & \\
\hline
\end{tabular}
encontram-se na tabela 3 .
TABELA 1

Critério de Resposta DAS OU DAS28 do EULAR

TABELA 2

ÍNDICE SIMPLIFICADO E CLÍNICO DE ATIVIDADE DE DOENÇA

\begin{tabular}{lccc}
\hline Medida & Parâmetro & SDAI & CDAI \\
\hline Número de articulações dolorosas & $\mathrm{N}=28$ & + & + \\
$\begin{array}{l}\text { Número de articulações edemaciadas } \\
\begin{array}{l}\text { Avaliação da atividade de } \\
\text { doença-paciente }\end{array}\end{array}$ & $\mathrm{N}=28$ & + & + \\
$\begin{array}{l}\text { Avaliação da atividade de } 0-10 \\
\text { doença-médico }\end{array}$ & EVA: $0-10$ & + & + \\
\begin{tabular}{l} 
Proteína C reativa \\
\hline
\end{tabular} & $0,1-10 \mathrm{mg} / \mathrm{dL}$ & + & + \\
\hline
\end{tabular}

TABELA 3

ÍNDICES COMPOSTOS DE ATIVIDADE DE DOENÇA COM SEUS DIFERENTES VALORES DE CORTE

\begin{tabular}{lccc}
\hline Índice & $\begin{array}{c}\text { Categoria de } \\
\text { atividade de doença }\end{array}$ & $\begin{array}{c}\text { Definição } \\
\text { original }\end{array}$ & $\begin{array}{c}\text { Nova definição } \\
\text { proposta* }\end{array}$ \\
\hline DAS & Remissão & $<1,6$ & - \\
Baixa & Moderada & $\leq 2,4$ & - \\
DAS28 & Alta & $\leq 3,7$ & - \\
& Remissão & $>3,7$ & - \\
& Baixa & $\leq 2,6$ & $\leq 2,4$ \\
SDAI & Moderada & $\leq 3,2$ & $\leq 3,6$ \\
& Alta & $\leq 5,1$ & $\leq 5,5$ \\
& Remissão & $>5,1$ & $>5,5$ \\
& Baixa & $<5$ & $<3$ \\
& Moderada & $\leq 20$ & $\leq 11$ \\
CDAI & Alta & $\leq 40$ & $>26$ \\
& Remissão & $>40$ & - \\
& Baixa & $<2,6$ & - \\
& Moderada & $\leq 1,0$ & - \\
& Alta & $\leq 22$ & - \\
\hline
\end{tabular}

*Adaptado de Aletaha e Smolen 9 .

Diversos estudos têm demonstrado que esses ICADs correlacionam-se de maneira muito elevada entre si, podendo ser empregados indistintamente, à escolha do médicoassistente?.

Os ICADs permitem, tanto aos médicos quantos aos pacientes, terem uma meta terapêutica, um alvo a ser alcançado. Assim como a dosagem da glicemia de jejum e 
a medida dos níveis da pressão arterial sistêmica são úteis para o controle dos pacientes diabéticos e hipertensos, respectivamente, o valor do ICAD deve ser utilizado para nortear o tratamento dos pacientes reumatóides ${ }^{9}$.

Apesar de sua grande importância, os ICADs possuem algumas limitações e certos cuidados precisam ser tomados.

Em relação à contagem de articulações dolorosas, como os ICADs foram elaborados a partir da análise de pacientes de AR com pouco tempo de evolução, a dor, quando presente, traduzia predominantemente o processo inflamatório. Em pacientes com longo tempo de evolução, apresentando graus variados de destruição e ou deformidades articulares, a dor pode não traduzir, necessariamente, atividade de doença. Vale lembrar que, se a dor for identificada, mesmo que não sugira inflamação das estruturas articulares, deve ser considerada, para fins do cálculo do índice, como presente.

Da mesma forma, a observação de edema articular constitui-se num achado positivo, independentemente de parecer ou não uma "sinovite residual", sem atividade inflamatória ativa. Em contrapartida, o aumento de volume articular secundário à deformidade articular e ou à eventual osteoartrite associada não deve ser considerado para o cálculo das articulações com edema.

\section{REFERÊNCIAS}

1. Andrade CAF, Pinheiro GRC, Figueiredo RC, et al.: Perfil epidemiológico dos pacientes com artrite reumatóide acompanhados no ambulatório da Disciplina de Reumatologia da Universidade do Estado do Rio de Janeiro. Rev Bras Reumatol 38: S-44, 1998.

2. Pinheiro GRC, Rebello MA, Andrade DO, Gandelsman A, Gaya VC: Investigating the role of rheumatologists in musculoskeletal disease management in the city of Rio de Janeiro. Ann Rheum Dis 62(Suppl I): 534, 2003

3. Emery P, Breedveld FC, Dougados M, Kalden JR, Schiff MH, Smolen JS: Early referral recommendations for newly diagnosed rheumatoid arthritis: evidence based development of a clinical guide. Ann Rheum Dis 61: 290-97, 2002.

4. Nell VPK, Machold KP, Eberl G, Stamn TA, Uffmann M, Smolen JS: Benefit of very early referral and very early therapy with disease-modifying anti-rheumatic drugs in patients with early rheumatoid arthritis. Rheumatology 43: 906-14, 2004.
Em alguns casos, quando o componente emocional se mostra relevante, em particular, quando ansiedade ou depressão estão presentes, a contagem das articulações dolorosas, a avaliação global da saúde e da atividade de doença pelo paciente não traduzem, necessariamente, o processo inflamatório reumático. Seguindo o mesmo raciocínio, os pacientes fibromiálgicos também merecem atenção especial.

A avaliação da atividade de doença pelo médico pode e deve levar em consideração todas as limitações descritas anteriormente, bem como eventuais parâmetros laboratoriais presentes no momento da consulta.

É de fundamental importância chamar a atenção dos colegas para a necessidade de termos um parâmetro de referência para guiar nossa conduta terapêutica diante de um paciente com AR. Em particular, quando do emprego de um agente biológico, não podemos deixar de utilizar um ICAD para indicar início e manutenção.

Procure escolher o ICAD que lhe pareça mais apropriado e participe dessa nova era do tratamento dos pacientes de AR. Melhore, ainda mais, a qualidade de seu atendimento. Seu paciente, seguramente, vai agradecer-lhe.

5. van der Heidjde DMFM: Joint erosions and patients with early rheumatoid arthritis. Br J Rheumatol 34(suppl 2): 74-8, 1995.

6. Breedveld FC, Kalden JR: Appropriate and effective management of rheumatoid arthritis. Ann Rheum Dis 63: 627-33, 2004.

7. Felson DT, Anderson JJ, Boers M, et al.: American College of Rheumatology preliminary definition of improvement in rheumatoid arthritis. Arthritis Rheum 38: 727-35, 1995.

8. van der Heidjde DMFM, van't Hof MA, van Riel PLCM, van de Putte LBA: Development of a disease activity score based on judgment in clinical practice by rheumatologists. J Rheumatol 20: 579-81, 1993.

9. Aletaha D, Smolen JS: The Simplified Disease Activity Index (SDAI) and the Clinical Disease Activity Index (CDAI): A review of their usefulness and validity in rheumatoid arthritis. Clin Exp Rheumatl 23(Suppl 39): S100-8, 2005. 
A seguir, apenas como sugestão, uma ficha clínica útil para a avaliação dos pacientes e registro dos ICADs.

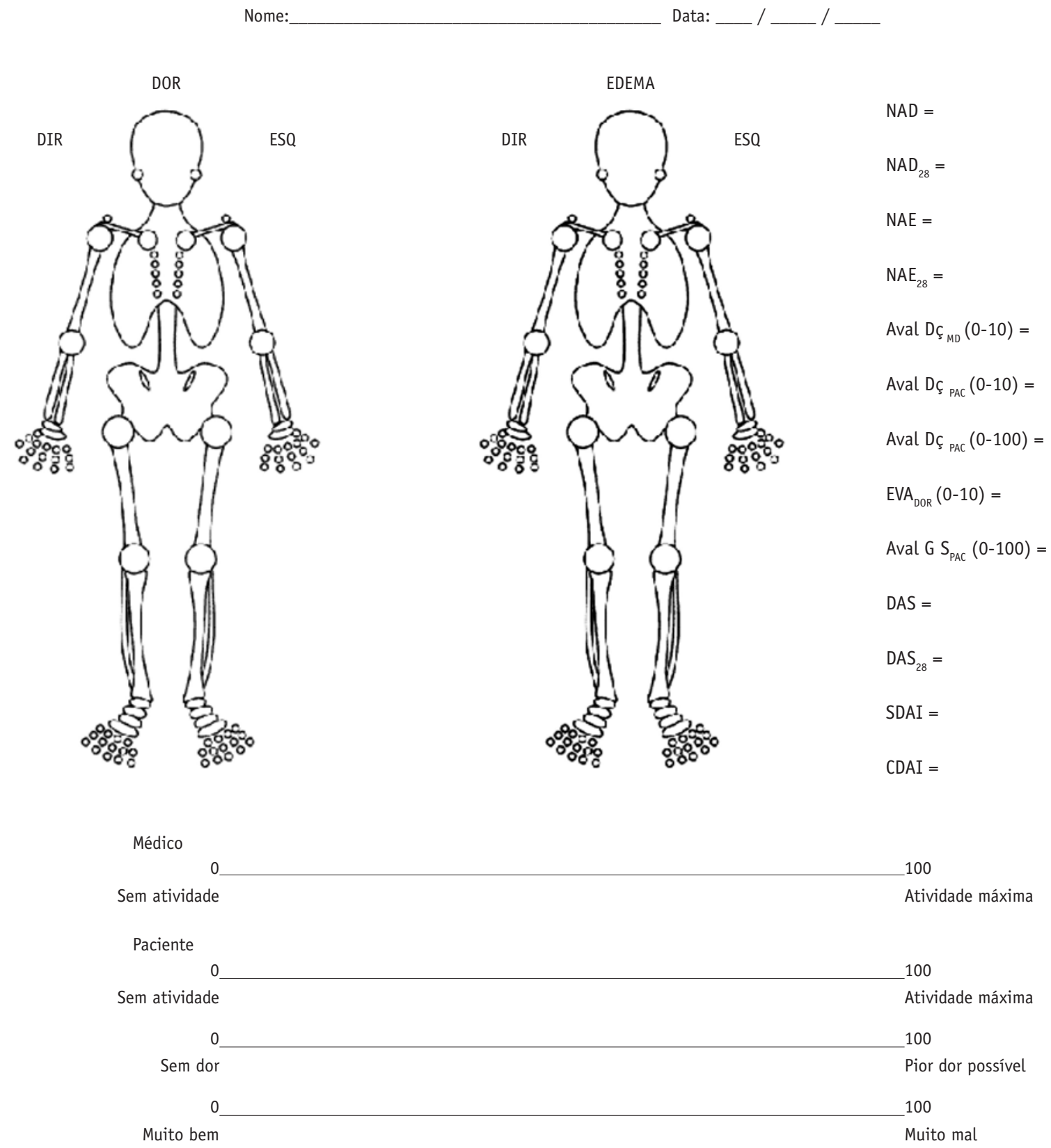

